\title{
IKERLANAK
}

\section{HUMAN CAPITAL AND MARKET SIZE}

by

Cecilia Vives

2016

Working Paper Series: IL. 98/16

Departamento de Fundamentos del Análisis Económico I

Ekonomi Analisiaren Oinarriak I Saila

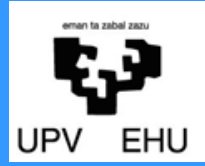

University of the Basque Country 


\title{
Human Capital and Market Size
}

\author{
Cecilia Vives*广 \\ University of the Basque Country UPV/EHU
}

July 2016

\begin{abstract}
This paper studies how the size of the labour market affects workers' decision to invest in human capital. We consider a model of mismatch where firms rank workers according to their level of skills. The matching process operating in the market has the property that the job finding probability of workers depends on market size, market tightness and their ranking. An interesting feature is that, while the job finding probability of workers with a given rank differs with market size, the probability of workers with a given level of human capital is constant with the size of the market. The model is consistent with several facts highlighted in empirical studies: In bigger markets the distribution of human capital is more unequal and the returns to skill are higher. We find numerically that the mean level of human capital increases with market size.
\end{abstract}

Keywords: Human Capital, Skill Distribution, City Size, Matching

JEL Classification: J24, R23

${ }^{*}$ I would like to thank Salvador Ortigueira, Javier Fernández Blanco, Diego Puga, Belén Jerez, Alfredo Salgado, Ilaski Barañano and Marta San Martín for their helpful comments and suggestions. Financial support from the Departamento de Educación, Política Lingüística y Cultura del Gobierno Vasco (IT869-13) is gratefully acknowledged.

${ }^{\dagger}$ Departamento de Fundamentos del Análisis Económico I, University of the Basque Country UPV/EHU, Avenida Lehendakari Agirre 83, 48015 Bilbao, Spain. E-mail address: cecilia.vives@ehu.eus 


\section{Introduction}

The distribution of human capital differs across cities (Lindley and Machin, 2014). It has been found that some of this spatial variation in skills is associated with size: Bigger cities have a higher mean and a higher dispersion of human capital than cities of smaller size (Gautier and Teulings, 2009).

These patterns can be the result of workers' migration or differences in workers' human capital investment. The literature has focused so far on the first possibility, with models where skills are exogenous and where some element makes bigger cities attract (or repel) workers with a particular level of skills. In contrast with them, the objective of this paper is to study the effect of city size on human capital investment. There are several reasons why human capital investment is important in this context: First, most of the literature that studies the spatial allocation of skills uses education attainment as a measure of human capital. But the education level can be, in part, decided by the individual. Second, Combes et al. (2012) find a small role for migration in accounting for the difference in skills between denser and less dense areas. Third, changes in human capital investment have implications that do not arise with changes in location. The endogeneity of human capital implies that city size may be a determinant of the distribution of skills of the entire economy.

Bigger cities have bigger labour markets. There is evidence that bigger labour markets facilitate the matching between workers and firms (Bleakley and Lin, 2012; Gan and Li, 2016). Since firms can find workers more easily, they can be more selective about whom to hire, which benefits the workers with a higher level of skills. This idea is consistent with the finding of positive assortative matching in bigger cities (Andersson et al., 2007). Therefore, a likely reason for workers investing more in human capital in bigger cities is that in those places the matching of skilled workers is easier. In this paper we formalise this idea by means of a model of mismatch.

The reason for this approach is motivated by recent research. Shimer (2007) shows that, in a mismatch model where the number of workers and vacancies are random, an increase in the size of local labour markets reduces the unemployment and vacancy rates. Furthermore, this mismatch model is consistent with the behaviour of the labour market at the aggregate level. Similarly, Gan and Li (2016) show that in a bigger market the probability of a match is larger using a model where the productivities of workers and vacancies are random.

In our setting, the number of workers and vacancies in the market are random. 
Workers are ex ante identical but can invest in human capital before entering the labour market. If there is an excess of workers, the ones with the lowest level of skills will be unemployed. There is perfect competition in the labour market. In this model, the concept of market size is related to the mean number of workers and vacancies in the market. Specifically, we define market tightness as the ratio of the mean number of vacancies to the mean number of workers. Then, the size of the market is large if the mean number of workers is large, for a given level of market tightness.

We allow for the dispersion in the number of workers and vacancies to depend on the size of the market. However, we assume that this relationship is such that the coefficient of variation is decreasing in market size. We provide empirical evidence on the variability of unemployment and vacancies in support of this assumption.

Under this setting, investing in human capital is more profitable if the job finding probability is higher. Therefore, we find that the effect of market size on the distribution of human capital depends on its effect on the job finding probability. In turn, the effect on the job finding probability depends on the rank of the worker. If the worker has a high rank, the probability is increasing with market size. Thus, a worker with high rank chooses a higher level of human capital in bigger markets. On the other hand, if the worker has a low rank, the job finding probability is decreasing in market size. Therefore, he invests less in human capital when the market is bigger. Market tightness determines the proportion of workers that belong to one group or the other.

These results imply that the model generates a more unequal distribution of skills in bigger markets. This is consistent with the evidence in Gautier and Teulings (2009), who report that in denser regions the dispersion of human capital is higher, and Eeckhout et al. (2014), who find that bigger cities have a higher proportion of workers with the highest and lowest educational groups. However, the empirical evidence also suggests that bigger cities are more skilled, on average, than smaller ones (Gautier and Teulings, 2009; Davis and Dingel, 2014). In line with this, we show numerically that the mean level of human capital is increasing with market size.

An interesting result is that, in equilibrium, the job finding probability of a worker with a given level of human capital is independent of market size. This is because the distribution of human capital that arises in equilibrium is such that this fact is satisfied: Consider two markets that only differ in their size and compare the job finding probability of two workers with high rank, one is in the big market and the other in the small market. If they have the same rank in their respective markets, the worker in the bigger market has a higher job finding probability. However, if they have 
the same level of human capital, the one in the bigger market has a lower rank in his market and they both have the same job finding probability.

Our model also has implications on the expected wage of a worker with a given level of human capital. In this respect, it is consistent with the empirical evidence, which reports higher returns to skill in bigger cities (Wheeler, 2001; Rosenthal and Strange, 2008; Bacolod et al., 2009; Davis and Dingel, 2012; Groot and De Groot, 2014).

There have been several theories proposed that can explain why bigger cities are more skill abundant. In Davis and Dingel(2012; 2014) bigger cities are more productive and high skilled workers benefit more from the higher productivity in those locations. In particular, Davis and Dingel (2012) formalise the view that bigger cities are more productive because they facilitate the exchange of ideas. In Nocke (2006) and Behrens et al. (2014) the advantage of bigger cities comes from the fact that they have a larger demand for goods, which implies higher profits for more talented entrepreneurs. In contrast with them, Lee (2010) develops a model in which the size of cities affects individuals in their role as consumers. In his model bigger cities have a higher consumption variety, which benefits more high-skilled individuals because they have a higher income and, thus, consume more. On the other hand, Eeckhout et al. (2014) propose a model that deals with the higher inequality in skills in bigger cities. They explain this through complementarities between high skilled and low skilled workers in the production function.

Our paper differs from this literature in that our focus is on the human capital investment decision instead of the location decision. The idea that market size can affect human capital accumulation has been previously explored in Kim (1989) and Redding and Schott (2003). Kim (1989) analyses the trade-off between general and specific human capital. Redding and Schott (2003) develop a model in which skilled-intensive production has increasing returns to scale. However, in this latter case the analysis is at the country level and they only allow for two levels of human capital, whereas in our model the distribution is continuous. Instead, the human capital investment decision in our model is closely related to Moen (1999). This paper studies human capital investment and its relationship with the socially optimal level when there is unemployment. In this formulation workers invest in human capital in order to increase their job finding probability. An interesting feature is that, departing from a situation with identical workers, the distribution of human capital that arises is non-degenerate. Our model also shares this characteristic. However, in Moen (1999) the job finding probability, and thus, the distribution of human capital, is unaffected by the size of the 
labour market.

In our paper, we investigate the role of matching as a source of the differences in the human capital distribution across locations. This mechanism has been studied as a potential source of agglomeration economies. An example of this is found in Wheeler (2001), who considers a model of search with heterogeneous workers and firms and finds that search frictions imply that productivity is increasing with city size. On the other hand, Gautier and Teulings (2009) propose a model to quantify the role of search in generating wage inequality across cities of different size. They consider workers who are heterogeneous in their level of skills and allow for migration. One of the implications of their model is that bigger cities specialise in the production of goods that require workers whose skills are scarce. Both in Wheeler (2001) and Gautier and Teulings (2009) it is assumed that bigger cities facilitate the meeting of workers and jobs. Therefore, our paper contributes to this literature by building a model of mismatch with heterogeneous workers that endogenizes the relationship between the size of the labour market and the job finding probability.

Some of the papers we have mentioned have dealt with the relationship between city size and returns to skill. Wheeler (2001) and Davis and Dingel (2012) have found a positive relationship. On the other hand, Lee (2010) implies that returns to skill are decreasing with size. ${ }^{1}$

The rest of the paper is organized as follows. Section 2 describes the setting. In Section 3 we consider the problem of the workers. Section 4 deals with the equilibrium. In Section 5 we use the model to analyse the relationship between the size of the labour market, the distribution of human capital and wages. Finally, Section 6 concludes.

\section{Setting}

We analyse an economy that lasts for one period in which we can identify 3 stages: In the first stage a continuum of unemployed workers are born and vacancies are created. In the second stage, each worker decides how much human capital to accumulate. Finally, workers and vacancies go to the labour market in order to get matched and receive their payoffs.

We assume that the number of workers, $U$, and vacancies, $V$, is random and independently distributed. $U$ is normally distributed with mean $\bar{U}>0$ and variance $\sigma_{U}^{2}$ and

\footnotetext{
${ }^{1}$ Lee (2010) provides evidence that this is the case in the health sector.
} 
$V$ is normally distributed with mean $\bar{V}>0$ and variance and $\sigma_{V}^{2}$. Let the associated distribution functions be denoted by $F_{U}(u)$ and $F_{V}(v)$. The assumption of a normal distribution is motivated by its analytical tractability and the fact that, when $\sigma_{U}^{2}=\bar{U}$ and $\sigma_{V}^{2}=\bar{V}$ for $\bar{U}$ and $\bar{V}$ large enough, the normal distribution is a good approximation to the Poisson distribution, previously used in Shimer (2007). However, as we show in Section 5, the results of the model do not depend on the normality assumption.

In the first stage, a realization of $U$ and $V$, which we will denote $u$, and $v$, is drawn. We assume that each firm has one vacancy, so referring to a vacancy or a firm is equivalent. At this stage workers are identical and do not know which realization has taken place.

In the second stage, the decision problem of each worker consists in choosing a costly level of human capital (or skill), $h$. Workers are risk neutral. The key assumption in this model is that the workers decide how much human capital to accumulate, they do not know $u$ and $v$. However, we assume that they know the distribution of these two variables. If we think of education as one of the main factors to acquire human capital, this assumption is reasonable. Individuals usually decide their level of human capital at early stages in life, without knowing the exact conditions of the labour market.

Each worker can accumulate a level of human capital $h \geq 0$ at a cost $C(h)$. The cost function is twice continuous differentiable and satisfies $C(0)=0, C^{\prime}(0)=0, C^{\prime}(h)>0$ for $h>0$, and $C^{\prime \prime}(h)>0$. We also assume that for some $h, C^{\prime}(h)>1$.

After the investment decision has taken place, all workers and firms observe $u$ and $v$ and enter the labour market in order to get matched. We assume perfect competition in the labour market. The chances of getting matched for a worker will depend on his level of human capital and on the realizations of $U$ and $V$. If a vacancy and a worker with a level of human capital equal to $h$ match in the market, they together produce $h$ units of a homogeneous output. In this case, the payoff of the worker will be $w \geq 0$ and the payoff of the firm will be $\pi=h-w \geq 0$. If a worker does not match any firm, he does not produce and receives 0 . Similarly, if a firm does not match any worker, profits are zero.

\section{Workers' Problem}

In this section, we will deal with the workers' problem. First, we will set the problem they face at the third stage, when they enter the labour market. We will derive which 
workers will be employed and at what wages. In the second part of this section, we will describe how workers choose their level of human capital.

\subsection{The Labour Market}

When the agents enter the labour market, the level of human capital of all workers is already determined. Let $G(h)$ denote the cumulative distribution function over human capital that arises in equilibrium. $G=G(h)$ can also be considered as the ranking of the worker, with higher $G$ meaning a higher ranking. Initially, we will assume that this distribution is continuous with a bounded support. We will denote the minimum level of $h$ in equilibrium $h_{\min }$ and the maximum $h_{\max }$.

There is perfect competition in the labour market. Firms seek to maximize their profits and workers seek to maximize their wage. In this setting, the number of matches will equal $\min \{u, v\}$ and firms employ the most productive workers ${ }^{2}$, that is, firms rank the workers according to their level of human capital. This last result and continuity of the distribution of human capital imply that a worker with a level of skills $h_{0}$ will find a job if there are more vacancies than workers with a higher level of skills than him, which can be expressed as $\left(1-G\left(h_{0}\right)\right) u \leq v$.

The payoffs of the workers depend on the the level of human capital of the worker with the lowest level among those employed. We will refer to this worker as the marginal worker and denote his level of skills as $h_{m}(u, v)$. The payoffs in equilibrium of a worker, when there are $u$ workers and $v$ vacancies in the market, is $w(h, u, v)$ and is given by:

$$
w(h, u, v)= \begin{cases}h & \text { when } u<v \\ h-h_{m}(u, v) & \text { when }(1-G(h)) u \leq v \leq u \\ 0 & \text { when } v<(1-G(h)) u\end{cases}
$$

This function is derived in Appendix A. The payoff function states that if there is an excess of jobs, $v>u$, workers' wage is their productivity. However, if there is an excess of workers, $v \leq u$, the worker is employed only if $(1-G(h)) u \leq v$; then the wage of an employed worker is the difference between his productivity and the productivity of the marginal worker.

\footnotetext{
${ }^{2}$ If $v<u$, the workers with higher human capital are employed. If this is not true, then there is some $h^{\prime}$ and $h^{\prime \prime}$ with $h^{\prime}>h^{\prime \prime}$ and $h^{\prime \prime}$ is employed but $h^{\prime}$ is not. This implies that $\pi\left(h^{\prime}, u, v\right) \leq \pi\left(h^{\prime \prime}, u, v\right)$, thus $w\left(h^{\prime}, u, v\right)>w\left(h^{\prime \prime}, u, v\right) \geq 0$ but in this case $h^{\prime}$ strictly prefers to be employed while it is not. This cannot be an equilibrium.
} 


\subsection{Workers' Expected Earnings}

At the second stage of the period, workers choose the level of human capital that maximizes their expected earnings. The worker only knows the distributions from where $u$ and $v$ will be drawn. Notice that the lack of information at the second stage of the process is the only source of friction in this economy. Once the agents go to the market, the matching process is efficient, both in generating the maximum number of matches possible and in selecting the most productive workers. The expected earnings, $\mathcal{E}(h)$, is a function of $h$, defined as:

$$
\mathcal{E}(h)=\mathbb{E}[w(h, U, V)]-C(h)
$$

where $\mathbb{E}[\cdot]$ is the expectation operator.

As it can be seen from (1), the expected payoff depends on the job finding probability of the worker. For a worker with $\operatorname{rank} G=G(h)$, this is the probability that $(1-G) u \leq$ $v$. Let denote it as $P(G)$. In Lemma 1 we show that the job finding probability is strictly increasing in $G$. This result is important to ensure that $G(h)$ is continuous in equilibrium.

Lemma 1. $P(G)$ is a continuous function, strictly increasing and differentiable in $G \in[0,1]$. Furthermore, $P(0)>0$.

Proof. See Appendix B.

We will next decompose the job finding probability in such a way that we can calculate the expected earnings. First of all, since the problem of the worker is to choose $h$, we must make explicit again the dependence of $G$ on $h$. Lemma 1 implies that $P(G(h))$ can be expressed as:

$$
P(G(h))=P(0)+\int_{h_{m i n}}^{h} P^{\prime}(G(\widetilde{h})) G^{\prime}(\widetilde{h}) d \widetilde{h}
$$

To simplify notation, let $p_{h}(h)=P^{\prime}(G(h)) G^{\prime}(h)$. Then,

$$
P(G(h))=P(0)+\int_{h_{\min }}^{h} p_{h}(h) d \widetilde{h}
$$

According to this equation, $P(G(h))$, can be calculated as the sum of two terms. The first term is the probability that $(1-G(h)) u \leq v$ for $G(h)=0$, which is the probability that there is an excess of vacancies. The second term is the integral of $p_{h}(h)$, 
which is the density of $(1-F(h)) u=v$, that is, of $h$ being the marginal worker. This definition of the job finding probability allows us to calculate the expected earnings of a worker as:

$$
\mathcal{E}(h)=P(0) h+\int_{h_{\text {min }}}^{h} p_{h}(\widetilde{h})(h-\widetilde{h}) d \widetilde{h}-C(h)
$$

The first term of the equation accounts for the wage when there is an excess of vacancies. And the second term accounts for the case when there is an excess of workers and $h$ finds a job for all possible values of the marginal worker. Notice that equation (3) also defines the expected earnings for $h<h_{\min }$ and $h>h_{\max }$.

The decision problem of the worker is:

$$
\max _{\{h \geq 0\}}\{\mathcal{E}(h)\}
$$

The worker takes $G(h)$ and $w(h, u, v)$ as given.

\section{Equilibrium}

An equilibrium solution to the problem outlined above can be described by a tuple $(G(h), w(h, u, v))$ such that:

1. $w(h, u, v)$ satisfies (1).

2. Workers solve (4).

3. $G(h)$ satisfies $\mathcal{E}\left(h_{1}\right)=\mathcal{E}\left(h_{2}\right)$ for $\forall h_{1}, h_{2}$ on the support of $G(h)$ and $\mathcal{E}(h)<$ $\mathcal{E}\left(h_{1}\right)$ for $\forall h$ that does not belong to the support.

The third point is due to the fact that, ex ante, all the individuals are equal. Thus, in equilibrium they all must obtain the same expected earnings. For any $h$ not in the support, the expected earnings must be lower. Given that the support of $G(h)$ is connected, this third condition implies that the derivative of the expected earnings with respect to human capital is zero for any $h$ in the support of $G(h)$. This derivative is:

$$
\frac{\partial \mathcal{E}(h)}{\partial h}=P(0)+\int_{h_{m i n}}^{h} p_{h}(\widetilde{h}) d \widetilde{h}+h p_{h}(h)-p_{h}(h) h-C^{\prime}(h)=0
$$


Notice that terms 3 and 4 account for the increment in the job finding probability, what is referred to as the rat race. However, at this point the worker is the marginal worker and his wage is 0 . Therefore, the gain from increasing the probability of finding a job is 0 . This means that, in contrast with Moen (1999), in this setup the ranking of workers does not produce rat race. On the contrary, each worker chooses the optimal level of $h$ given his job finding probability. Substituting (2), it simplifies to:

$$
\frac{\partial \mathcal{E}(h)}{\partial h}=P(G(h))-C^{\prime}(h)=0
$$

Therefore, in equilibrium:

$$
P(G(h))=C^{\prime}(h)
$$

This condition means that the marginal cost of acquiring an extra unit of human capital must equal the marginal benefit, which is simply $P(G(h))$. The individuals with a higher ranking will enjoy a higher probability of finding a job, which increases expected earnings. However, in equilibrium, all individuals must obtain the same expected earnings. Compare two workers with different levels of human capital. One worker has a higher position in the ranking than the other and a higher probability of finding a job. How much more human capital than the other he has does not affect the probability, since it only depends on the relative position in the ranking of each of them. In order for the low skilled worker to be willing to remain low skilled, the high skilled worker must accumulate a quantity of human capital such that the cost associated to it makes the expected earnings of both workers equal. Therefore, expected earnings are equalised through the cost of obtaining human capital. The following proposition shows that there exists a function $G(h)$ that satisfies equation (5) and that when the distribution of human capital is given by $G(h)$, the economy is in equilibrium.

Proposition 1. An equilibrium of the model exists with the associated distribution of human capital satisfying $P(G(h))=C^{\prime}(h) . G(h)$ is a continuous distribution.

Proof. See Appendix B.

Proposition 1 shows that the distribution of human capital only depends on the job finding probability and the marginal cost. The marginal cost is exogenous but the job finding probability depends on the ranking of the workers and the distribution of $U$ and 
$V$. Since we are interested in the effect of the size of the labour market on $G(h)$, we need to relate it to the distributions of $U$ and $V$. We had denoted the mean of $U$ by $\bar{U}$ and the mean of $V$ by $\bar{V}$. Now, let $\bar{V}=\theta \bar{U}$ with $\theta>0$. We can interpret $\bar{U}$ as market size and $\theta$ as market tightness.

\section{The Effect of Market Size on the Distribution of Human Capital and Wages}

We have seen that the size of the labour market can affect the distribution of human capital if it affects the job finding probability. Therefore, we begin by studying this latter relationship.

We allow the standard deviation of $U$ and $V$ to depend on their means. Therefore, let $\sigma_{U}=s(\bar{U})$ and $\sigma_{V}=s(\theta \bar{U})$, with $s()$ a differentiable function. This assumption implies that the coefficients of variation of $U$ and $V$ are also functions of $\bar{U}$ and $\theta \bar{U}$. We denote the coefficient of variation of $U$ as $c v(\bar{U})=\frac{s(\bar{U})}{\bar{U}}$. The following result shows that the effect of market size on the job finding probability of a worker with rank $G=G(h)$ depends on this coefficient.

Proposition 2. Consider $U \sim N(\bar{U}, s(\bar{U}))$ and $V \sim N(\theta \bar{U}, s(\theta \bar{U}))$ :

a) If $c v(\bar{U})$ is strictly increasing in $\bar{U}$, the job finding probability of a worker with ranking $G>(<) 1-\theta$, is strictly decreasing (increasing) with market size and the job finding probability of a worker with ranking $G=1-\theta$ is constant.

b) If $c v(\bar{U})$ is strictly decreasing in $\bar{U}$, the job finding probability of a worker with ranking $G>(<) 1-\theta$, is strictly increasing (decreasing) with market size and the job finding probability of a worker with ranking $G=1-\theta$ is constant.

c) If $c v(\bar{U})$ is constant in $\bar{U}$, the job finding probability is unaffected by market size.

Proof. See Appendix B.

If the coefficient of variation is strictly decreasing, bigger markets imply a higher job finding probability for the workers with higher rank and a lower job finding probability for the workers with lower rank. If the coefficient of variation is strictly increasing, the opposite occurs. That is, skilled workers benefit more from bigger markets if these kinds of markets are less variable than smaller ones. We look at the relationship between the 
coefficient of variation and market size in the data, with time series at the regional level. Given that we are interested in the variability of the series rather than on their levels, we find more appropriate to use data from administrative sources rather than surveys. Specifically, we use the monthly data for Spain from the Servicio Público de Empleo Estatal (SEPE) for the 52 provinces and autonomous cities for the period 2006-2015. SEPE provides data on labour supply, unemployment and the inflow of labour supply for each month. We use these three variables as measures of $u$. For the number of vacancies, we only have information of the inflow of vacancies created each month. We compute the mean and the coefficient of variation of these variables for each region. Figure 1 suggests a negative relationship between the coefficient of variation and the mean of both inflow of labour supply and inflow of vacancies. The same occurs for the variables labour supply and unemployment, represented in Figure 4 in Appendix C.

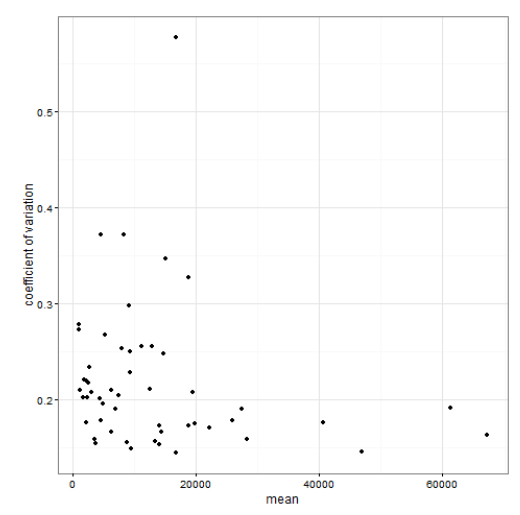

(a) Inflow of labour supply

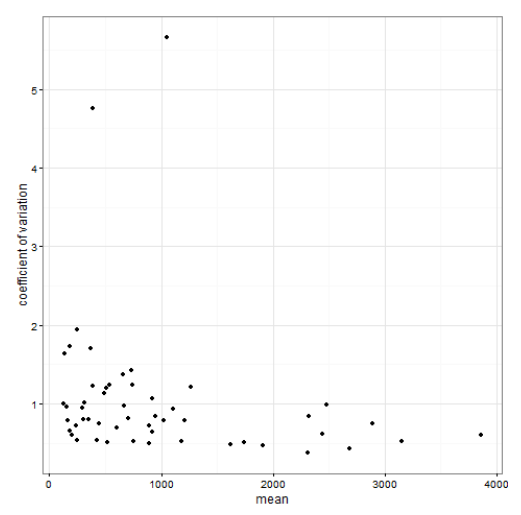

(b) Inflow of vacancies

Figure 1: Coefficient of variation for the Spanish provinces

Given this evidence, we will focus in the case of a decreasing coefficient of variation. Notice that, if we use the normal distribution as an approximation of the Poisson distribution (which is the distribution used in Shimer, 2007 and Mortensen, 2009), the coefficient satisfies this assumption.

The level of market tightness also plays an important role in the relationship between market size and the job finding probability. The larger is $\theta$ the higher the proportion of workers who will have a higher probability in a bigger market. In particular, if $\theta>1$, all workers have $G>1-\theta$. Thus, all of them will have a higher probability when the market is bigger. However, the data on vacancies and unemployment points to a level of market tightness slightly below 1 (Shimer, 2007). Therefore, from now on we will focus on the case of $\theta<1$. 
Assumption 1. $c v(\bar{U})$ is strictly decreasing in $\bar{U}$ and $\theta<1$.

An interesting outcome of the model is that, while workers with the same rank $G$ have different job finding probabilities in markets of different size, workers with the same level of human capital do not. This can be seen with Equation (5). The job finding probability of a worker with human capital $h$ must always be equal to the marginal cost of acquiring $h$, irrespectively of the size (or the tightness) of the market.

In Figure 2, we represent the job finding probability as a function of $G$ for the case in which $U \sim N(\bar{U}, \sqrt{\bar{U}})$ and $V \sim N(0.6 \bar{U}, \sqrt{0.6 \bar{U}})$, that is, market tightness is 0.6 and $s(x)=\sqrt{x}$. Consistent with Proposition 2, the job finding probability is higher in bigger markets when $G>1-\theta=0.4$ and lower when $G<0.4$.

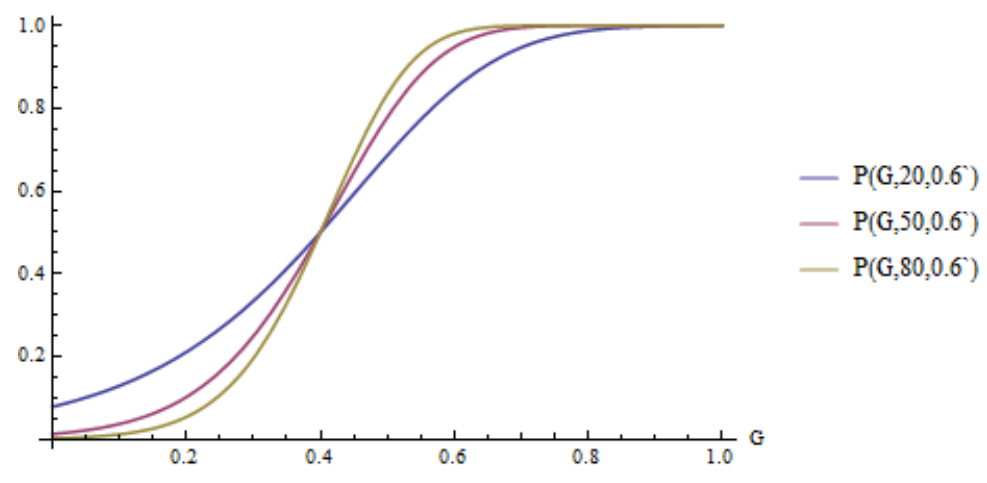

Figure 2: Job finding probability, $P(G, \bar{U}, \theta)$ for $U \sim N(\bar{U}, \sqrt{\bar{U}})$ and $V \sim$ $N(0.6 \bar{U}, \sqrt{0.6 \bar{U}})$

The result in Proposition 2 is not due to the assumption of normality. To see that, we also calculate the job finding probability when $U$ and $V$ follow a Gamma distribution. We use the same numerical example as in Figure 2. The parameters of the distribution are chosen so that $\sigma_{U}=\sqrt{\bar{U}}$ and $\sigma_{V}=\sqrt{\theta \bar{U}}$. This implies that the shape parameter is $\bar{U}$ for the case of $U$ and $\bar{V}$ for the case of $V$ while the scale parameter is 1 in both cases. The probability under these assumptions is represented in Figure 5 in Appendix C. The pattern is the same as for the Normal distribution. Furthermore, we also compute the job finding probability if $U$ and $V$ follow a Uniform distribution with support $[\bar{U}-10, \bar{U}+10]$ and $[\theta \bar{U}-10, \theta \bar{U}+10]$. This case also satisfies a decreasing coefficient of variation for $U$ and $V$ and, as it can be seen in Figure 5, is also consistent with the results in Proposition 2. 


\subsection{The Distribution of Human Capital}

The effect of market size on the distribution of human capital is driven by the effect on the job finding probability. If market size increases, the probability for the workers with rank below $1-\theta$ decreases. This means that their marginal benefit of investing in human capital is lower. In order for the marginal cost to be also lower, their level of human capital must decrease. On the contrary, for the workers with rank above $1-\theta$, the job finding probability increases with market size. Therefore, they choose a higher level of $h$. Proposition 3 formalises this result.

Proposition 3. Consider $U \sim N(\bar{U}, s(\bar{U}))$ and $V \sim N(\theta \bar{U}, s(\theta \bar{U}))$ and let cv $(\bar{U})$ and $\theta$ satisfy Assumption 1. Let $h_{0}$ be such that $G\left(h_{0}\right)=1-\theta$. Then,

a) $G(h)$ is strictly increasing in $\bar{U}$ for $h<h_{0}$, strictly decreasing in $\bar{U}$ for $h_{0}<h$ and constant for $h_{0}$.

b) $h_{\text {min }}$ is strictly decreasing in $\bar{U} . h_{\max }$ is strictly increasing in $\bar{U}$.

c) As $\bar{U}$ tends to infinity the distribution converges to a discrete distribution with a proportion $\theta$ of workers with $h=h_{\max }$ and $1-\theta$ of workers with $h=0$.

Proof. See Appendix B.

The existing empirical evidence on the distribution of human capital across cities suggests that the distribution of human capital tends to be more unequal in bigger cities. Gautier and Teulings (2009), using a measure of human capital that takes into account years of schooling and experience, find that the dispersion of human capital is increasing with city size. Eeckhout et al. (2014) use different variables to measure skills. In the case of education, they find that both the highest and the lowest skilled workers are disproportionately more frequent in larger cities. They also measure skills indirectly through wages, finding that the distribution has thick tails in large cities. These results are in line with Combes et al. (2012), who also use information on wages for France. However, this indirect evidence should be interpreted with a bit of caution, since it requires assuming that returns to skill are constant with city size, and this does not seem to be the case. However, studies that follow other approaches also suggest higher inequality in bigger cities. This is the case of Bacolod et al. (2009), who use AFQT scores to measure the level of skills, and find that in a larger city the 90th percentile have lower scores than in a smaller city while the 10th percentile have higher scores. In contrast with these studies, Wheeler (2001) estimates a negative relationship between 


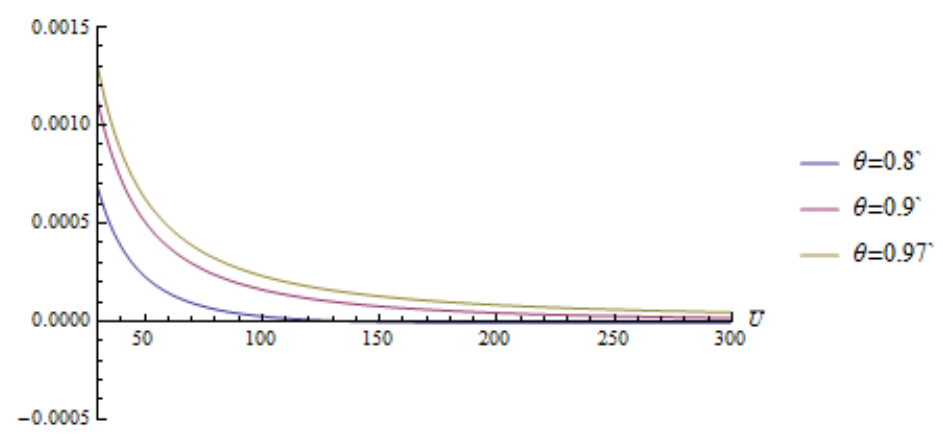

Figure 3: Derivative of the mean level of $h$ with respect to market size for $U \sim$ $N(\bar{U}, \sqrt{\bar{U}})$ and $V \sim N(\theta \bar{U}, \sqrt{\theta \bar{U}})$

the percentage of population with low levels of education and population but he only uses 3 educational groups. Davis and Dingel (2014) find that population elasticities are monotonically increasing in educational attainment. However, the elasticities that they estimate for the two lowest educational groups (out of 9) are slightly higher than for the immediate superior educational group ${ }^{3}$. This suggests that intermediate skilled groups are not disproportionality located in bigger cities compared with the lowest skilled groups. Our model is consistent with this evidence.

Gautier and Teulings (2009) also reports that the mean level of education is increasing with the size of the market. We calculate this relationship in the model numerically. We have represented in Figure 3 the derivative of the mean level of human capital as a function of market size for different levels of market tightness. The minimum level of market size chosen is 30 since the normal distribution is only a good approximation of the Poisson distribution when $\bar{U}$ and $\bar{V}$ are big enough. On the other hand, Shimer (2007), with US data for the period 2000-2006, calculates $\bar{V}=236.3$ and $\bar{U}=244.2$, which imply a level of market tightness of 0.97 .4 The size of the market that he reports is within the range of the graph and we have also included the case of $\theta=0.97$. The cost function used is $C(h)=\frac{1}{2} h^{2}$. The figure shows that the mean level of human capital is increasing with market size.

\footnotetext{
${ }^{3}$ They find that, for one of these two groups, this is the case even when they restrict the sample to US-born individuals.

${ }^{4}$ In his notation, $V$ refers to the jobs that are vacant after the matching process has taken place. The number of jobs available to be matched (our $\bar{V}$ ) are denoted by $N$.
} 


\subsection{The Expected Wage}

In this section we look at the effect of market size on the expected wage. The expected wage of a worker with human capital $h$ is the expected payoff conditional on finding a job. Let denote it as $w^{e}(h)$ :

$$
w^{e}(h)=\frac{\mathbb{E}[w(h, U, V)]}{P(G(h))}
$$

The expected payoff, $\mathbb{E}[w(h, U, V)]$, can be derived from the equilibrium condition that equalises the expected earnings of all workers. Since the expected earnings of the worker at the bottom of the distribution are easier to compute, we will use $\mathcal{E}(h)=$ $\mathcal{E}\left(h_{\text {min }}\right)$. Substituting $\mathcal{E}(h)=\mathbb{E}[w(h, U, V)]-C(h)$ into this equilibrium condition, we obtain $\mathbb{E}[w(h, U, V)]=\mathcal{E}\left(h_{\text {min }}\right)+C(h)$.

Thus, the expected wage becomes:

$$
w^{e}(h)=\frac{\mathcal{E}\left(h_{\text {min }}\right)+C(h)}{P(G(h))}
$$

Since we are interested in the effect of market size on $w^{e}(h)$, we need to know how it affects $P(G(h))$ for a worker with a given level of human capital. Equilibrium condition (5) implies that market size does not affect the job finding probability. Since $P(G(h))=C^{\prime}(h)$, when market size increases, the ranking of the worker will change so that the job finding probability always equals the marginal cost. Therefore, the effect of market size on the expected wage depends on the effect of market size on the expected earnings of the worker at the bottom of the distribution. When market tightness is below 1 the expected earnings of this worker are decreasing with market size, because his job finding probability is decreasing. Therefore, the expected wage of all workers is lower in bigger markets.

Proposition 4. Let $c v(\bar{U})$ and $\theta$ satisfy Assumption 1. Then, $w^{e}(h)$ is decreasing with market size.

Proof. See Appendix B.

This result relates with the findings of Baum-Snow and Pavan (2012) on the city size wage premium. They estimate a structural model to investigate the role of different mechanisms in generating this premium. They include the search and matching mechanism by allowing for differences across locations in the arrival and separation rates 
from jobs and in the standard deviation of the worker-firm specific component of the wage. They find little contribution of this mechanism to the city size wage premium. Our model can provide part of the explanation for their finding. The model implies that the job finding probability of workers with the same level of human capital is the same in small and large cities. Therefore, it suggests that there should not be significant differences in the arrival rate from jobs across locations. However, our model does not include heterogeneity on the firm side and, thus, is silent on the potential role of assortative matching (Wheeler (2001)).

\subsection{Returns to Skill}

Some empirical studies have focused on whether returns to skills are larger in bigger cities. Using education as a measure of skills, most of the literature finds that this is the case (Wheeler, 2001; Rosenthal and Strange, 2008; Bacolod et al., 2009 and Davis and Dingel, 2012 for the US and Groot and De Groot, 2014 for the Netherlands). Our model also generates a positive effect of market size on expected returns to skill.

Proposition 5. Let $c v(\bar{U})$ and $\theta$ satisfy Assumption 1. Then, expected returns to skill are increasing with market size.

Proof. See Appendix B.

The intuition of this result can be understood with the equilibrium condition. The expected earnings must be the same for all workers. As market size increases, the expected earnings of the worker at the bottom decreases. Therefore, the expected earnings of all workers must decrease in the same quantity. Since the cost of acquiring human capital is unaffected by market size, the expected payoffs of all workers must also decrease in the same quantity. For a worker with low $h$, the job finding probability is small. Therefore, the expected wage must decrease more in order to obtain the same reduction in the expected payoff.

Recent research is focusing on the dynamic effects of city size on the urban wage premium. This is the case of Wheeler (2006) and Baum-Snow and Pavan (2012) for the US, Carlsen et al. (2013) for Norway and De la Roca and Puga (2012) for Spain. These studies have found that wage growth is higher in bigger cities. This can be interpreted as evidence of greater "learning" or improved matches in bigger cities. However, it can also 
be interpreted as further evidence of higher returns to skill in bigger cities. Consider the case in which the skills acquired with experience are included in the concept of human capital. Then, the higher slope in wage profiles in bigger cities can be due to bigger cities rewarding more the higher level of skills associated with experience. In particular, the finding in De la Roca and Puga (2012) that the experience accumulated in smaller cities is more valued in bigger cities would point to that direction.

\section{Conclusions}

In this paper, we have explored the relationship between the size of the labour market and human capital investment. To this end, we have developed a model in which workers' probability of getting a job depends on the size of the market and workers' relative position in the distribution of skills. In bigger labour markets there is less variability (in relative terms) in the number of workers and jobs. This implies that workers with a high rank have a higher probability of finding a job whereas this probability is lower for workers with a low rank. The effect on the job finding probability is translated into the human capital investment decision.

The predictions of the model are consistent with the empirical evidence at the city level. We find that the mean level of human capital and returns to skill are increasing with market size. The model also implies that in bigger labour markets the workers at the bottom of the distribution have lower levels of human capital.

Our framework contributes to the understanding of the matching mechanism and uncovers an interaction between the job finding probability, market size and market tightness. In addition, the result of higher returns to skill in bigger markets suggests a new channel through which city size affects earnings growth. We leave the role of returns to skill on the relationship between market size and wage dynamics as a topic for future research. 


\section{References}

Andersson, F., S. Burgess, and J. I. Lane (2007). Cities, matching and the productivity gains of agglomeration. Journal of Urban Economics 61(1), 112-128.

Bacolod, M., B. S. Blum, and W. C. Strange (2009). Skills in the city. Journal of Urban Economics 65(2), 136-153.

Baum-Snow, N. and R. Pavan (2012). Understanding the city size wage gap. Review of Economic Studies 79(1), 88-127.

Behrens, K., G. Duranton, and F. Robert-Nicoud (2014). Productive cities: Sorting, selection, and agglomeration. Journal of Political Economy 122(3), 507-553.

Bleakley, H. and J. Lin (2012). Thick-market effects and churning in the labor market: Evidence from us cities. Journal of Urban Economics 72(2-3), 87-103.

Carlsen, F., J. Rattsø, and H. E. Stokke (2013). Education, experience and dynamic urban wage premium. Norwegian University of Science and Technology Working Paper 14/2013.

Combes, P.-P., G. Duranton, L. Gobillon, and S. Roux (2012). Sorting and local wage and skill distributions in france. Regional Science and Urban Economics 42(6), 913930.

Davis, D. R. and J. I. Dingel (2012). A spatial knowledge economy. NBER Working Paper 18188.

Davis, D. R. and J. I. Dingel (2014). The comparative advantage of cities. NBER Working Paper 20602.

De la Roca, J. and D. Puga (2012). Learning by working in big cities. CEPR Discussion Papers 9243.

Eeckhout, J., R. Pinheiro, and K. Schmidheiny (2014). Spatial sorting. Journal of Political Economy 122(3), 554-620.

Gan, L. and Q. Li (2016). Efficiency of thin and thick markets. Journal of Econometrics 192(1), 40-54. 
Gautier, P. A. and C. N. Teulings (2009). Search and the city. Regional Science and Urban Economics $39(3), 251-265$.

Groot, S. and H. L. De Groot (2014). Estimating the skill bias in agglomeration externalities and social returns to education: Evidence from dutch matched worker-firm micro-data. Tinbergen Institute Discussion Papers 14-088/VIII.

Kim, S. (1989). Labor specialization and the extent of the market. Journal of Political Economy 97(3), 692-705.

Lee, S. (2010). Ability sorting and consumer city. Journal of Urban Economics 68(1), 20-33.

Lindley, J. and S. Machin (2014). Spatial changes in labour market inequality. Journal of Urban Economics 79, 121-138.

Moen, E. R. (1999). Education, ranking, and competition for jobs. Journal of Labor Economics 17(4), 694-723.

Mortensen, D. T. (2009). Island matching. Journal of Economic Theory 144(6), 23362353.

Nocke, V. (2006). A gap for me: Entrepreneurs and entry. Journal of the European Economic Association 4(5), 929-956.

Redding, S. and P. K. Schott (2003). Distance, skill deepening and development: Will peripheral countries ever get rich? Journal of Development Economics 72(2), 515541.

Rosenthal, S. S. and W. C. Strange (2008). The attenuation of human capital spillovers. Journal of Urban Economics 64(2), 373-389.

Shimer, R. (2007). Mismatch. American Economic Review 97(4), 1074-1101.

Wheeler, C. H. (2001). Search, sorting, and urban agglomeration. Journal of Labor Economics 19(4), 879-899.

Wheeler, C. H. (2006). Cities and the growth of wages among young workers: Evidence from the nlsy. Journal of Urban Economics 60(2), 162-184. 


\section{A Payoffs}

Let profits be denoted by $\pi(h, u, v)=h-w(h, u, v)$.

a) When $u<v$ : There will be unmatched vacancies. For firms to remain indifferent about their vacancies being unmatched, profits must be zero for all firms. Therefore, $w(h, u, v)=h$.

b) When $(1-G(h)) u \leq v \leq u$ : We derive the wage of the marginal worker first. To simplify notation, let $h_{m}(u, v)=h_{m}$. If $w\left(h_{m}, u, v\right)=\epsilon>0$, given that the distribution of human capital has a connected support, there is an unemployed worker with $h^{\prime}=h_{m}-\epsilon^{\prime}$ and $0 \leq \epsilon^{\prime}<\epsilon$. In equilibrium this worker must be indifferent about being unemployed, so his wage is 0 . But this implies, $\pi\left(h^{\prime}, u, v\right)>\pi\left(h_{m}, u, v\right)$, which is not possible in equilibrium. Therefore, $w\left(h_{m}, u, v\right)=0$. To derive the wage of all the workers with a level of human capital above the marginal worker, note that firms must be indifferent about whom to hire, so for any $h^{\prime}, h^{\prime \prime} \geq h_{m}, \pi\left(h^{\prime}, u, v\right)=\pi\left(h^{\prime \prime}, u, v\right)$. In particular, if $h^{\prime \prime}=h_{m}$, $\pi\left(h^{\prime}, u, v\right)=\pi\left(h_{m}, u, v\right)=h_{m}$. Therefore, $w\left(h^{\prime}, u, v\right)=h^{\prime}-h_{m}$.

c) When $v<(1-G(h)) u$ : The worker is unemployed and obtains the payoff $w(h, u, v)=0$.

\section{B Proofs}

\section{Proof of Lemma 1:}

Let $X=(1-G) U-V$. Then, $X$ is normally distributed with mean $\mu=(1-G) \bar{U}-\bar{V}$ and variance $\sigma^{2}=(1-G)^{2} \sigma_{U}^{2}+\sigma_{V}^{2}$. Denote the associated distribution function by $F_{X}(x)$. The job finding probability is given by:

$$
P(G)=F_{X}(0)=\Phi\left(-\frac{\mu}{\sigma}\right)=\Phi\left(\frac{\bar{V}-(1-G) \bar{U}}{\left((1-G)^{2} \sigma_{U}^{2}+\sigma_{V}^{2}\right)^{1 / 2}}\right)
$$

The derivative is:

$$
P^{\prime}(G)=\phi\left(\frac{\bar{V}-(1-G) \bar{U}}{\left((1-G)^{2} \sigma_{U}^{2}+\sigma_{V}^{2}\right)^{1 / 2}}\right) \frac{\bar{U} \sigma_{U}^{2}+(1-G) \bar{V} \sigma_{V}^{2}}{\sigma^{3}}>0
$$




\section{Proof of Proposition 1:}

1. $G(h)$ that satisfies equation (5) exists and is a continuous distribution:

In Lemma 1 it is shown that $P(G)$ is strictly increasing for $G \in[0,1]$. Therefore, in equation (5), we can invert $P(G)$ and obtain $G(h)=P^{-1}\left(C^{\prime}(h)\right)$ for $h \in\left[h_{\text {min }}, h_{\text {max }}\right]$, with $h_{\text {min }}$ defined by $P(0)=C^{\prime}\left(h_{\min }\right)$ and $h_{\max }$ by $P(1)=$ $C^{\prime}\left(h_{\max }\right)$. Since $P(G)$ lies in $[0,1]$, the assumption that $C^{\prime}(h)$ continuous and ranging from 0 to a value greater than 1 guarantees the existence of $G(h)$. Since $P(G)$ and $C^{\prime}(h)$ are continuous and strictly increasing, $G(h)$ is a continuous distribution.

2. The equilibrium conditions are satisfied:

In section 4, we have shown that if $G(h)$ satisfies equation (5), then $\mathcal{E}\left(h_{1}\right)=\mathcal{E}\left(h_{2}\right)$ for any $h_{1}, h_{2} \in\left[h_{\text {min }}, h_{\text {max }}\right]$. But, given $h_{1} \in\left[h_{\text {min }}, h_{\text {max }}\right]$, we have to show that $\mathcal{E}(h)<\mathcal{E}\left(h_{1}\right) \forall h$ that does not belong to the support. There are two cases: $h<h_{\min }$ and $h>h_{\max }$.

(a) Case of $h<h_{\text {min }}$ : The expected earnings of a worker with $h \leq h_{\text {min }}$ are $\mathcal{E}_{h \leq h_{\text {min }}}(h)=P(0) h-C(h)$. Since $\mathcal{E}_{h \leq h_{\text {min }}}^{\prime \prime}(h)=-C^{\prime \prime}(h)<0$, the maximum of $\mathcal{E}_{h \leq h_{\text {min }}}(h)$ is achieved when $\mathcal{E}_{h \leq h_{m i n}}^{\prime}(h)=P(0)-C^{\prime}(h)=0$, that is, at $h_{\min }$.

(b) Case of $h>h_{\max }$. The expected earnings of a worker with $h \geq h_{\max }$ are:

$$
\begin{aligned}
\mathcal{E}_{h \geq h_{\text {max }}}(h) & =P(0) h+\int_{h_{\min }}^{h} p_{h}(\widetilde{h})(h-\widetilde{h}) d \widetilde{h}-C(h) \\
& =P(0) h+\int_{h_{\min }}^{h_{\text {max }}} p_{h}(\widetilde{h})(h-\widetilde{h}) d \widetilde{h}-C(h)
\end{aligned}
$$

The second equality is due to $p_{h}(h)=0$ for $h>h_{\max }$ since $G^{\prime}(h)=0$ in this range. Then,

$$
\mathcal{E}_{h \geq h_{\max }}^{\prime}(h)=P(0)+\int_{h_{\min }}^{h_{\max }} p_{h}(\widetilde{h}) d \widetilde{h}-C^{\prime}(h)=P(1)-C^{\prime}(h)
$$

Since $\mathcal{E}_{h \geq h_{\max }}^{\prime \prime}(h)=-C^{\prime \prime}(h)<0$, the maximum of $\mathcal{E}_{h \geq h_{\max }}(h)$ is achieved when $\mathcal{E}_{h \geq h_{\max }}^{\prime}(h)=0$, that is, at $h_{\max }$. 


\section{Proof of Proposition 2:}

Following the same procedure as in the proof of Lemma 1, the job finding probability can be expressed as:

$$
P(G)=\Phi\left(\frac{(\theta-(1-G)) \bar{U}}{\sigma(\bar{U})}\right)
$$

with $\sigma(\bar{U})=\left((1-G)^{2}(s(\bar{U}))^{2}+(s(\theta \bar{U}))^{2}\right)^{1 / 2}$

Therefore, the derivative of the job finding probability with respect to market size is given by:

$$
\frac{\partial P(G)}{\partial \bar{U}}=\phi(\cdot)(\theta-(1-G)) \frac{\sigma(\bar{U})-\bar{U} \sigma^{\prime}(\bar{U})}{(\sigma(\bar{U}))^{2}}
$$

We need to find the sign of $\sigma(\bar{U})-\bar{U} \sigma^{\prime}(\bar{U})$. Computing this term gives:

$$
\sigma(\bar{U})-\bar{U} \sigma^{\prime}(\bar{U})=(1-G)^{2} s(\bar{U})\left(s(\bar{U})-\bar{U} s^{\prime}(\bar{U})\right)+s(\theta \bar{U})\left(s(\theta \bar{U})-\theta \bar{U} s^{\prime}(\theta \bar{U})\right)
$$

Since $s()$ is the standard deviation, it is never negative. If $s(\bar{U})-\bar{U} s^{\prime}(\bar{U})>(<) 0$ for all $\bar{U}, s(\theta \bar{U})-\theta \bar{U} s^{\prime}(\theta \bar{U})$ is also positive (negative). Then, the sign of $\sigma(\bar{U})-\bar{U} \sigma^{\prime}(\bar{U})$ equals the sign of $s(\bar{U})-\bar{U} s^{\prime}(\bar{U})$. In turn, this is positive (negative) if $c v(\bar{U})$ is strictly decreasing (increasing) in $\bar{U}$.

\section{Proof of Proposition 3:}

a) Given a worker with human capital $h$, Equation (5) must be satisfied. Taking derivatives on both sides, we obtain:

$$
\frac{\partial G(h)}{\partial \bar{U}}=-\frac{\frac{\partial P(G(h))}{\partial \bar{U}}}{\frac{\partial P(G(h))}{\partial G(h)}}
$$

The denominator is always positive. The numerator is positive (negative) when $G>(<) 1-\theta$. Therefore $\frac{\partial G(h)}{\partial \bar{U}}$ is positive (negative) when $G<(>) 1-\theta$. If $h_{0}$ satisfies $G\left(h_{0}\right)=1-\theta$, then $h<(>) h_{0}$ when $G<(>) 1-\theta$.

b) $h_{\text {min }}$ satisfies $P(0)=C^{\prime}\left(h_{\text {min }}\right)$. Therefore,

$$
\frac{\partial h_{\min }}{\partial \bar{U}}=\frac{\frac{\partial P(0,)}{\partial \bar{U}}}{C^{\prime \prime}\left(h_{\min }\right)}
$$


This is negative when $\theta<1$.

$h_{\max }$ satisfies $P(1)=C^{\prime}\left(h_{\max }\right)$. Therefore,

$$
\frac{\partial h_{\max }}{\partial \bar{U}}=\frac{\frac{\partial P(1)}{\partial \bar{U}}}{C^{\prime \prime}\left(h_{\max }\right)}
$$

This is positive if $\theta>0$, which is always satisfied.

c) As $\bar{U}$ tends to infinity $P(G)$ tends to 1 for $G>1-\theta$. Therefore, $h$ tends to $h_{\max }=C^{\prime-1}(1)$ for $1-(1-\theta)=\theta$ of workers. As $\bar{U}$ tends to infinity, $P(G)$ tends to 0 for $G<1-\theta$. Therefore, $h$ tends to $h_{\text {min }}=C^{\prime-1}(0)=0$ for $(1-\theta)-0=\theta$ of workers.

\section{Proof of Proposition 4:}

The derivative of the expected wage is:

$$
\frac{\partial w^{e}(h)}{\partial \bar{U}}=\frac{1}{P(G(h))} \frac{\partial \mathcal{E}\left(h_{\min }\right)}{\partial \bar{U}}
$$

Since $\mathcal{E}\left(h_{\min }\right)=P(0) h_{\min }-C\left(h_{\min }\right)$. We have that:

$$
\frac{\partial \mathcal{E}\left(h_{\min }\right)}{\partial \bar{U}}=\frac{\partial P(0)}{\partial \bar{U}} h_{\min }
$$

When $\theta<1, \frac{\partial \mathcal{E}\left(h_{\min }\right)}{\partial \bar{U}}<0$. Therefore, the derivative of the expected wage is negative.

\section{Proof of Proposition 5:}

Let $h^{\prime}>h \geq 0$. The expected returns to skill are:

$$
\frac{w^{e}\left(h^{\prime}\right)-w^{e}(h)}{h^{\prime}-h}=\frac{\frac{\mathcal{E}\left(h_{\min }\right)+C\left(h^{\prime}\right)}{P\left(G\left(h^{\prime}\right)\right)}-\frac{\mathcal{E}\left(h_{\min }\right)+C(h)}{P(G(h))}}{h^{\prime}-h}
$$

Taking the derivative with respect to market size, we obtain:

$$
\frac{\partial\left(\left(w^{e}\left(h^{\prime}\right)-w^{e}(h)\right) /\left(h^{\prime}-h\right)\right)}{\partial \bar{U}}=\frac{\frac{1}{P\left(G\left(h^{\prime}\right)\right)}-\frac{1}{P(G(h))}}{h^{\prime}-h} \frac{\partial \mathcal{E}\left(h_{\text {min }}\right)}{\partial \bar{U}}
$$

This is the product of two terms. The first term is negative. In the Proof to Proposition 5 we found that $\frac{\partial \mathcal{E}\left(h_{\min }\right)}{\partial \bar{U}}<0$. Therefore, $\frac{\partial\left(\left(w^{e}\left(h^{\prime}\right)-w^{e}(h)\right) /\left(h^{\prime}-h\right)\right)}{\partial \bar{U}}>0$. 


\section{Additional Figures}

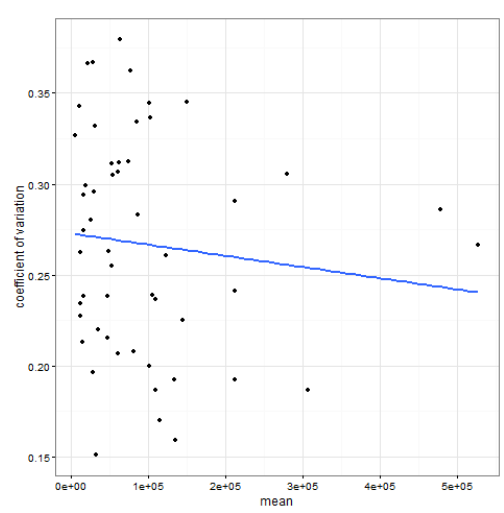

(a) Labour supply

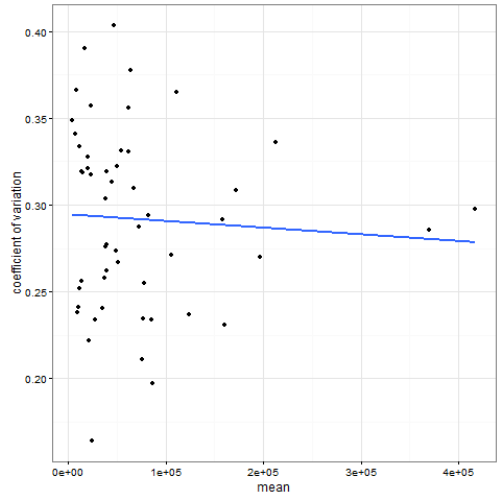

(b) Unemployment

Figure 4: Coefficient of variation

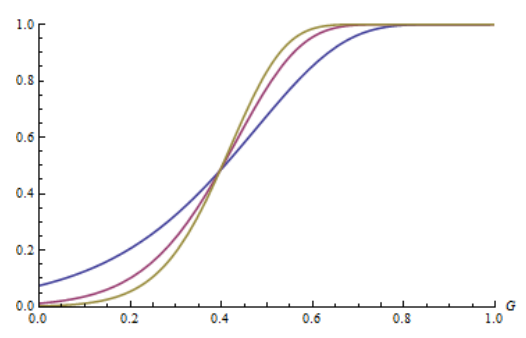

(a) Gamma distribution

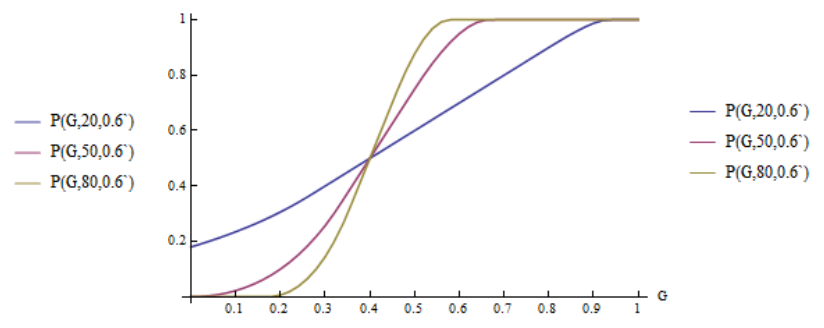

(b) Uniform distribution

Figure 5: Job finding probability, $P(G, \bar{U}, \theta)$. Gamma distribution: the shape parameter is $\bar{U}$ for the case of $U, \bar{V}$ for the case of $V$, and the scale parameter is 1 in both cases. Uniform distribution: support $[\bar{U}-10, \bar{U}+10]$ for $U$ and $[\theta \bar{U}-10, \theta \bar{U}+10]$ for $V$ 